J. Electroanal. Chem., 326 (1992) 105-112

Elsevier Sequoia S.A., Lausanne

JEC 01919

\title{
Raman spectra of zinc phthalocyanine monolayers adsorbed on glassy carbon and gold electrodes by application of a confocal Raman microspectrometer
}

\author{
B.J. Palys \\ Laboratory of Chemical Physics, Faculty of Chemical Technology, Twente University of Technology, \\ P.O. Box 217, 7500 AE Enschede (The Netherlands)
}

G.J. Puppels

Biophysical Technology Group, Faculty of Applied Physics, Twente University of Technology, P.O. Box 217, 7500 AE Enschede (The Netherlands)

D. van den Ham and D. Feil

Laboratory of Chemical Physics, Faculty of Chemical Technology, Twente University of Technology, P.O. Box 217, 7500 AE Enschede (The Netherlands)

(Received 23 July 1991; in revised form 4 November 1991)

\begin{abstract}
Raman spectra of zinc phthalocyanine monolayers, adsorbed on gold and on glassy carbon surfaces (electrodes), are presented. These spectra have been recorded with the electrodes inside and outside an electrochemical cell filled with an aqueous electrolyte. A confocal Raman microspectrometer was used. It was demonstrated that, because this spectrometer uses low laser intensities, no damage of the monolayer occurred. The results show that the interaction of the phthalocyanine molecule with gold diffcrs from that with glassy carbon. Because the laser excitation wavelength $(660 \mathrm{~nm})$ coincides with a UV-visible absorption band ( $Q$ band), a strong resonance-enhanced Raman spectrum was obtained. No signs of surface enhancement (surface-enhanced Raman scattering) effects were detected.
\end{abstract}

\section{INTRODUCTION}

Transition metal phthalocyanines, especially those with iron and cobalt, are interesting catalysts for the electroreduction of molecular oxygen [1-5]. The redox properties of these compounds adsorbed on carbon supports have been reported [2-6]. It has been shown that the interaction between adsorbate and support influences the electrocatalytic activity $[3,6]$, i.e. different carbon supports result in 
a different catalytic activity of the adsorbate. To study this support-adsorbate interaction, Raman scattering may be used.

Raman spectra of phthalocyanine (sub)monolayers adsorbed on noble metal electrodes have already been reported [7-9], but here we will present at the same time spectra of zinc phthalocyanine ( $\mathrm{ZnPc}$ ) adsorbed on gold and on glassy carbon electrodes that are placed in an aqueous electrolyte. These spectra were obtained by means of a recently developed confocal Raman microspectrometer (CRM) $[10,11] . \mathrm{ZnPc}$ itself has no electrocatalytic properties but it was chosen as a model compound to demonstrate that Raman spectra of adsorbed phthalocyanines can be obtained irrespective of the support material. The redox behaviour of $\mathrm{ZnPc}$ is relatively simple as oxidation occurs only with the organic ligand while alteration of the oxidation state of the central zinc ion is not likely. Moreover, we do not expect that Raman spectra of adsorbed $\mathrm{ZnPc}$ are affected by axial ligands such as oxygen, either inside or outside the electrochemical cell. Also, the UV-visible spectroscopic data of $\mathrm{ZnPc}$ in its reduced and oxidized forms have been tabulated [12-14]. On the basis of these data it will be shown that to obtain Raman spectra of $\mathrm{ZnPc}$ monolayers one has to ensure that resonance enhancement takes place. Finally we will show that interaction of $\mathrm{ZnPc}$ with the support is visible in the Raman spectrum.

\section{EXPERIMENTAL}

$\mathrm{ZnPc}$ was obtained commercially and utilized without further purification.

The $\mathrm{ZnPc}$ monolayer was obtained by immersing the support in a dilute solution of $\mathrm{ZnPc}$ in concentrated sulphuric acid. The electrode was immersed in water (millipore super Q) and treated in an ultrasonic bath for $5 \mathrm{~min}$. All supports were cleaned rigorously in concentrated sulphuric acid and boiled twice in (super Q) water. The amount of adsorbed $\mathrm{ZnPc}$ on the electrodes was calculated from the results of voltammetric and coulometric measurements. These experiments were carried out in a standard three-electrode cell with $0.1 \mathrm{M} \mathrm{HClO}_{4}$ as the supporting electrolyte and a mercury/mercury sulphate $/ \mathrm{K}_{2} \mathrm{SO}_{4}$ (sat) electrode (MSE) as the reference electrode.

Raman spectra of $\mathrm{ZnPc}$ monolayers on gold and glassy carbon clectrodes werc recorded both inside (in situ) and outside (ex situ) an electrochemical cell. The electrolyte, a nitrogen-saturated $0.1 \mathrm{M} \mathrm{HClO}_{4}$ solution, was pumped through the cell. All potentials quoted are measured against the MSE. A schematic representation of the experimental set-up for the in situ measurements is given in Fig. 1.

The CRM has been described in detail in ref. 10. Spectral resolution was $6-7 \mathrm{~cm}^{-1}$. A Spectra Physics model 375B dye laser $(660 \mathrm{~nm})$, operated with the laser dye 4-dicyanomethylene-2-methyl-6-[( $p$-dimethylamino)styryl]-4H-pyran, was used for excitation. Laser power at the sample was $2 \mathrm{~mW}$ in all experiments. A $\times 63 / 0.17$ microscope objective (numerical aperture, 0.85 ) was used to focus the light on the sample and to collect the scattered light. The irradiated spot on the sample has a diameter less than $1 \mu \mathrm{m}$. The confocal detection of scattered light 


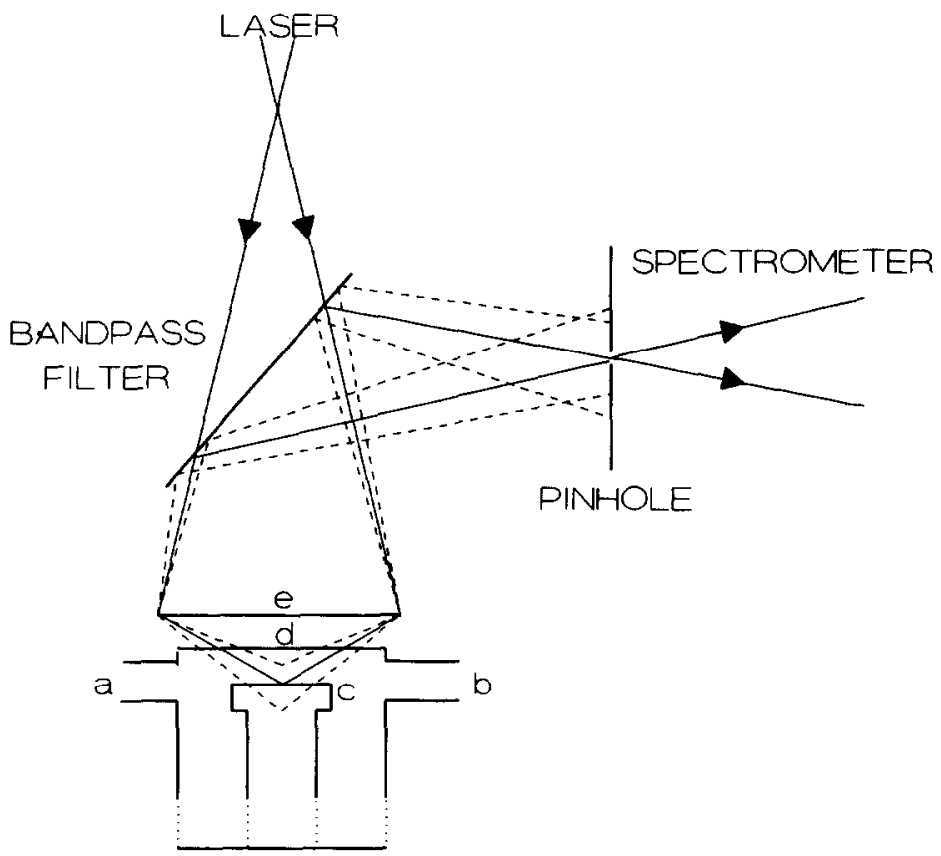

Fig. 1. Experimental set-up for in situ measurements using the CRM: - - , out-of-focus signal; a, reference electrode and electrolyte input; b, counterelectrode and electrolyte outlet; c, working electrode; $d$, optical glass window of the electrochemical cell; e, microscope objective.

restricted the effective measuring volume to roughly $1 \mu \mathrm{m}^{3}$. The Raman signal from the adsorbed layer passes through a pinhole in the image plane of the objective (Fig. 1) but background signals (from the solution and window of the electrochemical cell) are suppressed. The spectra of $\mathrm{ZnPc}$ on glassy carbon have been corrected for residual background signals. Wavenumber calibrations were made on the basis of the spectrum of indene, recorded at the same settings of the CRM as in the presented experiments. Peak positions are accurate within $2 \mathrm{~cm}^{-1}$.

\section{RESULTS AND DISCUSSION}

Cyclic voltammetry was used to check the thickness of the adsorbed $\mathrm{ZnPc}$ layers (Figs. 2 and 3). From these experiments it follows that the oxidation reaction is reversible. Because only one electron is involved in the oxidation of $\mathrm{ZnPc}$ [13] the number of adsorbed molecules can be calculated from the amount of charge that is transferred in the anodic or cathodic peak. Under the assumption of a perfect smooth surface, typical values for the number of $\mathrm{ZnPc}$ molecules on gold and glassy carbon were $3.5 \times 10^{13} \mathrm{~cm}^{-2}$ and $2 \times 10^{13} \mathrm{~cm}^{-2}$ respectively. From X-ray data [15] and with the approximation that a phthalocyaninc molcculc is a squarc 


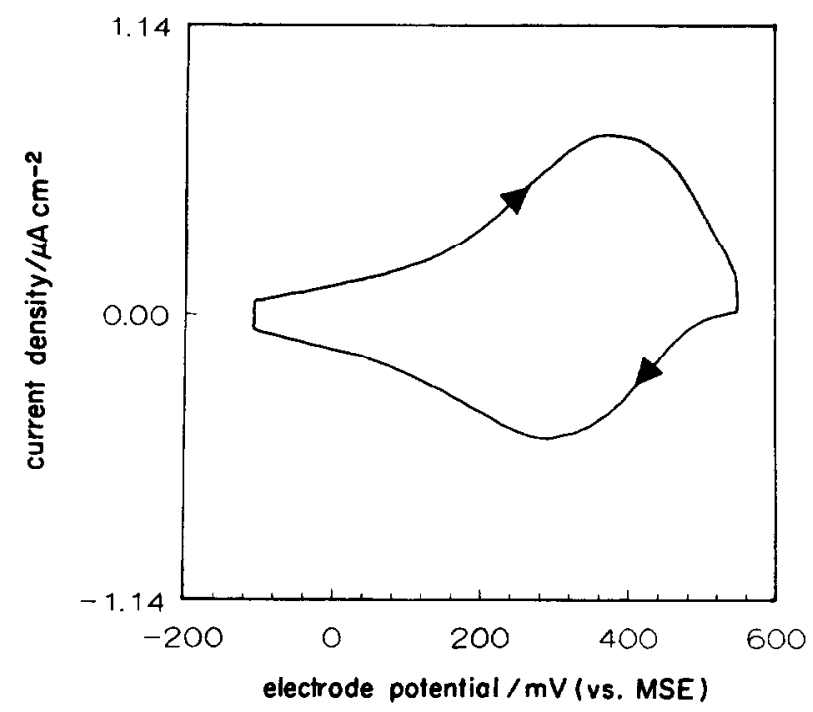

Fig. 2. The cyclic voltammogram of the $\mathrm{ZnPc}$ adsorbed on a glassy carbon electrode in $0.1 \mathrm{M} \mathrm{HClO}_{4}$. Scan rate, $80 \mathrm{mV} \mathrm{s}^{-1}$.

with an area of $200 \AA^{2}$ one calculates coverages of $70 \%$ and $40 \%$ for the gold and the glassy carbon electrodes respectively. We take these results as a proof that the adsorbed layers are (sub)monolayers indeed.

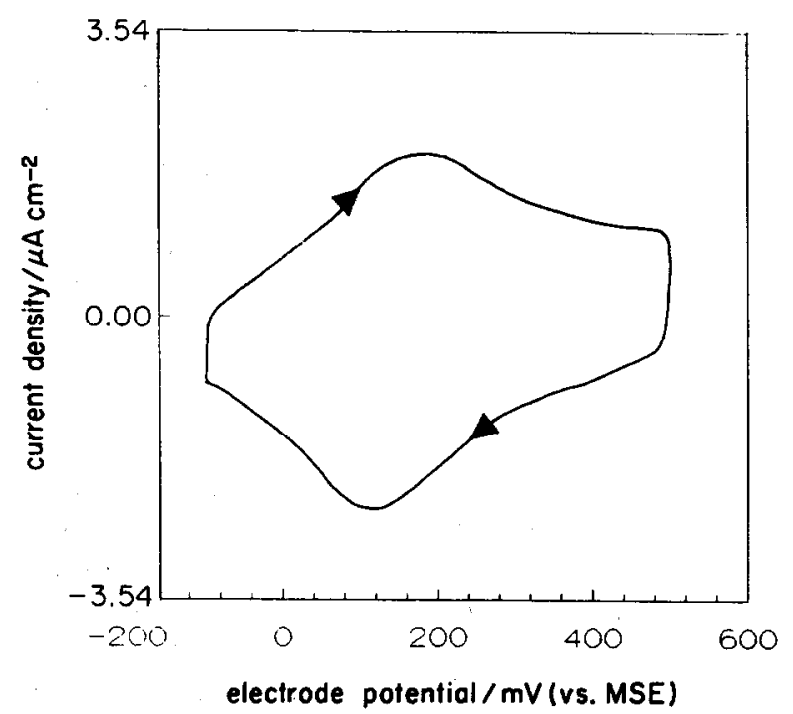

Fig. 3. The cyclic voltammogram of the $\mathrm{ZnPc}$ adsorbed on a gold electrode in $0.1 \mathrm{M} \mathrm{HClO}_{4}$. Scan rate, $80 \mathrm{mV} \mathrm{s}^{-1}$. 


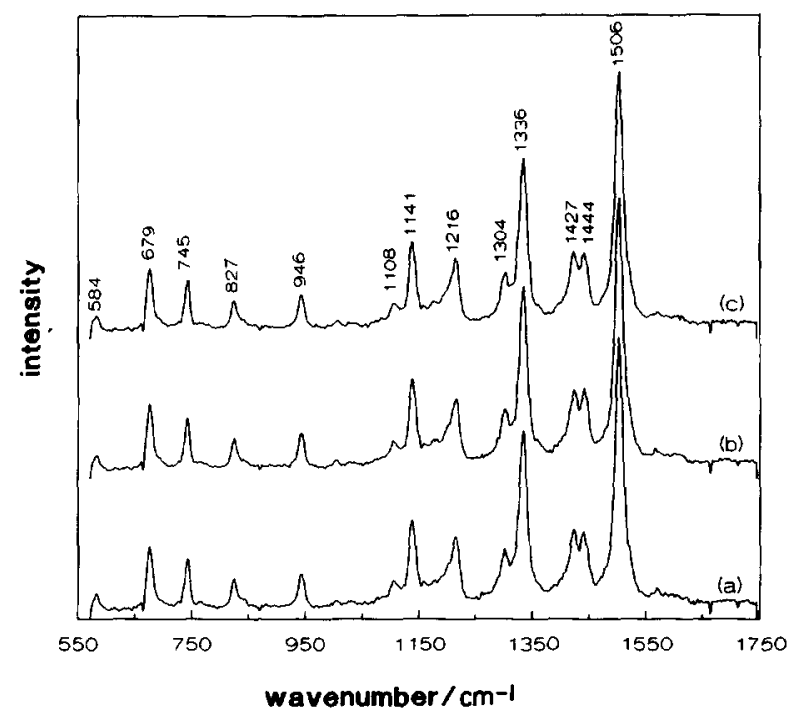

Fig. 4. In situ Raman spectra of a $\mathrm{ZnPc}$ monolayer on a glassy carbon electrode recorded at the open loop potential of $-30 \mathrm{mV}$. All these spectra were obtained at the same position on the electrode after (a) $2 \mathrm{~min}$, (b) $6 \mathrm{~min}$ and (c) $8 \mathrm{~min}$ of exposure to the laser light. Acquisition time for each spectrum, $10 \mathrm{~s}$.

We verified that damage of the adsorbed layer by the laser beam does not occur. In one experiment we kept the laser beam focused for $8 \mathrm{~min}$ at one point on the glassy carbon electrode surface. From Fig. 4 it can be seen that the $\mathrm{ZnPc}$ spectrum remained unaltered in shape and intensity.

Figures 5 and 6 show Raman spectra of adsorbed $\mathrm{ZnPc}$ on glassy carbon and gold electrodes at the open loop potential $(-30 \mathrm{mV}$ and $-100 \mathrm{mV}$ for glassy carbon and gold respectively) and at $350 \mathrm{mV}$ (MSE). At the latter potential most of the $\mathrm{ZnPc}$ molecules exist, according to Figs. 2 and 3, in their oxidized form. Also at this potential the Raman spectrum collapses. Switching the potential back to the original open loop value restores the original spectrum in shape and intensity. Two observations can be made: first, the oxidation of the $\mathrm{ZnPc}$ layer is reversible and the oxidized form remains adsorbed at the electrode surface and, second, only the neutral form contributes to the Raman spectrum. The second observation can be explained by the resonance character of the spectrum as follows. The $660 \mathrm{~nm}$ laser line coincides with the broad absorption band ( $\mathrm{Q}$ band) of neutral $\mathrm{ZnPc}$, and resonance enhancement can be expected. On oxidation this $Q$ band shifts considerably to shorter wavelengths $(550 \mathrm{~nm})[13,14]$ and resonance enhancement no longer occurs. To exclude the possibility that surface-enhanced Raman scattering (SERS) effects play a role, we also recorded the spectrum of $\mathrm{ZnPc}$ adsorbed on glass. As shown in Fig. 7, the intensities of the Raman spectra of $\mathrm{ZnPc}$ adsurbed 


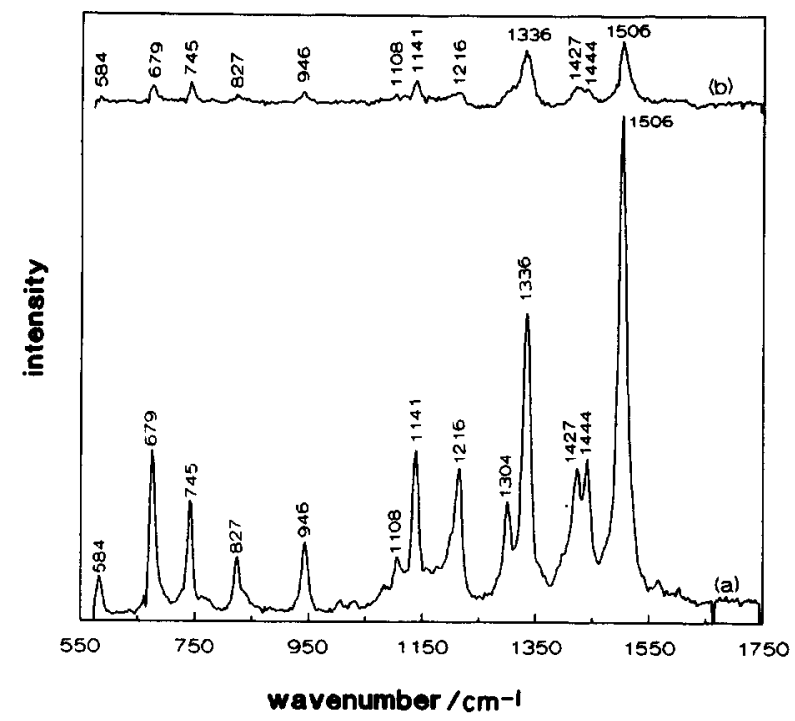

Fig. 5. In situ Raman spectra of a $\mathrm{ZnPc}$ monolayer deposited on a glassy carbon electrode, recorded at (a) open loop potential, equal to $-30 \mathrm{mV}$, and (b) a potential of $+350 \mathrm{mV}$. Acquisition times, $10 \mathrm{~s}$.

on glass, gold and on glassy carbon are of the same magnitude. Because of this and because of the fact that SERS effects on glass are not possible, only resonance enhancement is operative.

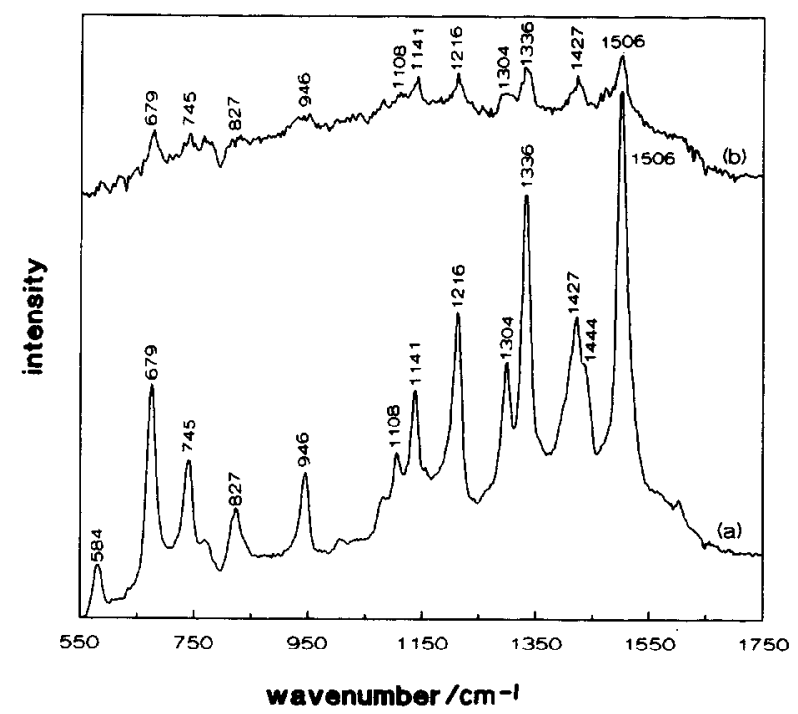

Fig. 6. In situ Raman spectra of a $\mathrm{ZnPc}$ monolayer deposited on a gold electrode, recorded at (a) open loop potential, equal to $-100 \mathrm{mV}$, and (b) a potential of $+300 \mathrm{mV}$. Acquisition times, $10 \mathrm{~s}$. 


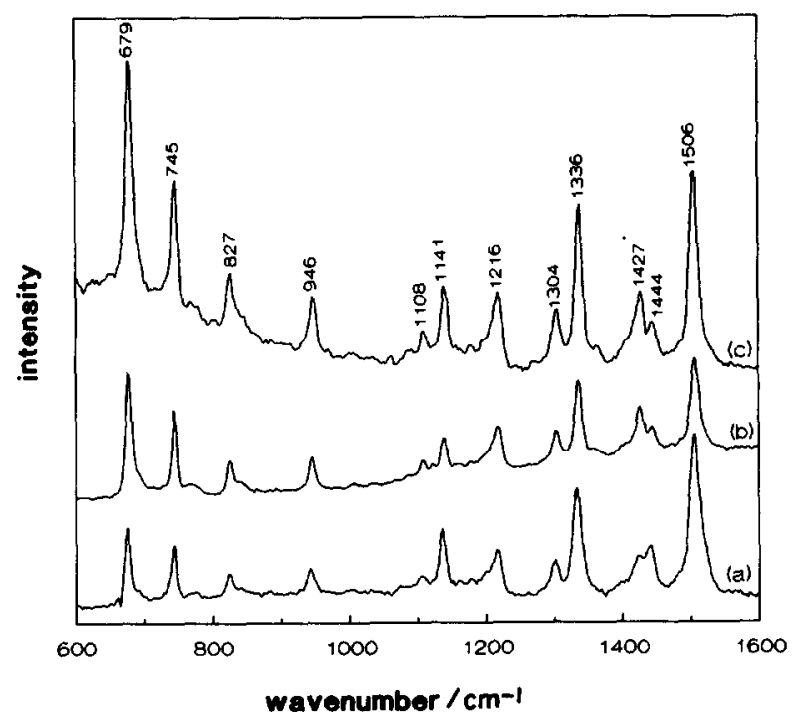

Fig. 7. Ex situ Raman spectrum of ZnPc monolayer deposited on (a) glassy carbon electrode, (b) microscope glass and (c) gold electrode. Acquisition times, $10 \mathrm{~s}$.

Analysis of the spectra of Fig. 7 also reveals differences that we attribute to differences in adsorbate-support interaction. Although peak positions are the same for all supports studied, peak intensities do vary. The peaks at 1335 and 1506 $\mathrm{cm}^{-1}$, the pyrrole stretching modes [16], are stronger in the case of the glassy carbon support than in the case of gold and glass supports. Comparison of the ex situ and in situ spectra of $\mathrm{ZnPc}$ on gold reveals an intensity increase for the pyrrole stretching modes in the latter case (Figs. 7(c) and 6). No such differences are observed with glassy carbon (Figs. 7(a) and 5). Support-specific differences are also found in the band around $1430 \mathrm{~cm}^{-1}$ (Figs. 5 and 6). The latter modes have been assigned to $\mathrm{C}-\mathrm{N}$ vibrations [16]. These observations suggest that the interaction with the support takes place via the nitrogen atoms of $\mathrm{ZnPc}$. In fact this conclusion has also been drawn by Coowar et al. [6] who studied the long-term electrochemical stability of adsorbates of iron naphthalocyanines on several different carbon supports and found that the stability of the adsorbate parallelled the surface concentration of acidic groups.

\section{REFERENCES}

1 H. Jahnke, M. Schonborn and G. Zimmermann, Top. Curr. Chem., 61 (1976) 133.

2 D. van den Ham, C. Hinnen, G. Magner and M. Savy, J. Phys. Chem., 91 (1987) 4743.

3 J.A.R. van Veen and C. Visser, Electrochim. Acta, 24 (1979) 921.

4 C. Hinnen, F. Coowar and M. Savy, J. Electroanal. Chem., 264 (1989) 167.

5 A. Biloul, F. Coowar, O. Contamin, G. Scarbeck, M. Savy, D. van den Ham, J. Riga and J.J. Verbist, J. Electroanal. Chem., 289 (1990) 189. 
6 F. Coowar, O. Contamin, M. Savy, G. Scarbeck, D. van den Ham, J. Riga and J.J. Verbist, J. Electroanal. Chem., 282 (1990) 141.

7 R. Kotz and E. Yeager, J. Electroanal. Chem., 113 (1980) 113.

8 C.A. Melendres, C.B. Rios, X. Feng and R. McMasters, J. Phys. Chem., 87 (1983) 3526.

9 R. Aroca, D. Battisti, G.J. Kovacs and R.O. Loutfy, J. Electrochem. Soc., 136 (1989) 2902.

10 G.J. Puppels, F.F.M. de Mul, C. Otto, J. Greve, M. Robert-Nicoud, D.J. Anndt-Jovin and T.M. Jovin, Nature (London), 347 (1990) 301.

11 G.J. Puppels, W. Colier, J.H.F. Olminkhof, C. Otto, F.F.M. de Mul and J. Greve, J. Raman Spectrosc., 22 (1991) 217.

12 E.A. Lucia and F.D. Verderame, J. Chem. Phys., 48 (1968) 2674.

13 J.M. Green and L.R. Faulkner, J. Am. Chem. Soc., 105 (1983) 2950.

14 P.C. Minor, M. Gouterman and A.B.P. Lever, Inorg. Chem., 24 (1985) 1984.

15 W.R. Scheidt and W. Dow, J. Am. Chem. Soc., 99 (1977) 1101.

16 C. Jennings, R. Aroca, A.-M. Hor and R.O. Loutfy, J. Raman Spectrosc., 15 (1984) 34. 